with the temperament to suffer from vaginismus are found to have married men who demand comparatively little. Organic causes of pain include a large or thick hymen, even occasionally an almost imperforate vagina; but generally an unruptured hymen is a consequence, not a cause, of superficial dyspareunia. Occasionally superficial dyspareunia develops because of a local infection or the presence of a painful scar, but these things present no problem either in diagnosis or in treatment.

\section{DEEP DYSPAREUNIA}

Pain deep in the pelvis, felt either at the time of intercourse or soon afterwards, usually has a demonstrable pathology. A retroverted uterus even when mobile may be associated with deep dyspareunia, because the ovaries can be trapped in the pouch of Douglas and pressed against the sacrum at intercourse. In these circumstances the dyspareunia may be intermittent, since it depends on the ovaries being trapped. In most cases the difficulty is relieved by coitus in the left lateral position. The therapeutic use of a Hodge pessary to antevert the uterus does not really advance the diagnosis, because intercourse may be incomplete with the pessary in situ. Permanent cure will usually be obtained by one of the operations to ventrosuspend the uterus.

Lesions in the pelvis such as endometriosis or sepsis may result in pain on intercourse, which can be reproduced on pelvic examination. Appropriate treatment usually brings relief. Finally, back lesions such as prolapsing discs or sacroiliac strains can give rise to pain after intercourse, which may be referred round into the abdomen. Characteristically this pain lasts for a day or more after the intercourse.

\section{Pelvic Congestion}

Many of woman's problems have been attributed to pelvic congestion associated with sexual frustration. It is difficult to know how much weight to attribute to such a factor when sexual frustration is so often symptomatic of a poor relationship and a more general discontent. Masters and Johnson ${ }^{5}$ were able to show a gradually developing but eventually intense pelvic vasocongestion, with enlargement of the uterus, in a woman subject to repeated pelvic examination and coital stimulation over a period of six hours. The congestion was relieved rapidly by orgasm.

It would not be surprising if such congestion, repeatedly induced by sexual stimulation but never relieved by a satisfactory climax, did ultimately produce physical problems such as lowgrade pain and menstrual abnormalities, but it is impossible to indicate how common such things are. In any event, good counselling of both partners will usually produce an improvement in general health and mental outlook that it will render comparatively minor physical disorders tolerable if it does not actually relieve them.

\section{References}

1 Dannreuth, W. T., American Fournal of Obstetrics and Gynecology, 1957,

74, 747.
2 Francis, J. A., and Jeffcoate, T. N. A., Fournal of Obstetrics and Gynaecology of the British Commonwealth, 1961, 68, 1.

${ }^{3}$ Frith, K. M., Fournal of Obstetrics and Gynaecology of the British Commonwealth, 1961, 68, 1033 .

4 Graber, E. A., Barber, H. K., and O'Rourke, J. J., Obstetrics and Gynecology, 1969, 33, 418 .

5 Masters, W. H., and Johnson, V. E., Human Sexual Inadequacy. Boston Little, Brown, 1970.

\title{
Approach to Rapid Problem Solving in Clinical Medicine
}

\section{B. J. ESSEX}

British Medical fournal, 1975, 3, 34-36

\section{Summary}

Problem-orientated flow charts have been developed to teach paramedical workers the skills of making diagnoses in outpatient clinics in Tanzania. The charts give high levels of repeatability, accuracy, and rapidity and their use may lead to improved standards of medical care.

\section{Introduction}

Most medical care in developing countries is provided in outpatient clinics, where large numbers of patients are seen in a short time. Most of this work is done by paramedical staff who undergo a three-year training programme which is almost exclusively hospital based. They are taught the skills of history taking and examination on patients admitted to health centres

Medical Faculty, University of Dar es Salaam, Tanzania

B. J. ESSEX, M.SC., M.R.C.P., Senior Lecturer in Community Medicine (Now Consultant to the African Medical and Research Foundation, Nairobi) or hospitals. Conventional methods of teaching these skills are important but time consuming. Moreover, after such teaching students often find that they are unable to diagnose the problems of all 150 to 200 patients seen each morning, which leads to frustration and cynicism about the use of much of their training and results in the symptomatic treatment of most illnesses with little attempt at differential diagnosis. A new technique has therefore been developed to teach the special diagnostic skills needed to practise effective outpatient medicine.

\section{Objectives and Method}

A project was undertaken to develop, test, and evaluate a method of diagnosis which would $(a)$ be problem orientated; $(b)$ have an acceptable level of accuracy; (c) be based on history taking and clinical examination alone; $(d)$ enable a diagnosis to be reached in under three minutes; $(e)$ be suitable for teaching paramedical and medical students; and $(f)$ have a high level of repeatability. It should also lead to a standardized pattern of referral to health centre or hospital. The technique was developed in the following four stages.

Identification of Symptoms. - A simple classification was developed to record the frequency of symptoms in children aged up to 4 years and 5 to 15 years and adults. This was used to record all symptoms in all patients attending the dispensary and health centre clinics 
during two periods in the wet and dry seasons. Altogether 3897 symptoms were identified in 2962 patients; 34 different symptoms were recorded.

Differential Diagnosis. - The differential diagnosis for each symptom was obtained by studying children and adults in hospital and outpatient clinics over a three-month period in the coastal region of Tanzania.

Selection of Diagnostic Discriminants. - The most discriminating symptoms and signs for rapid differential diagnosis were identified.

Construction of Diagnostic Pathway. - The way in which the discriminating symptoms and signs were used to develop a diagnostic pathway is shown in the flow chart for swelling of the legs in adults. Fifty-two such charts were designed, covering a total of 34 symptoms and 18 physical signs in children and adults. The charts incorporate 130 common diseases and health problems seen in Tanzania but do not include rare diseases.

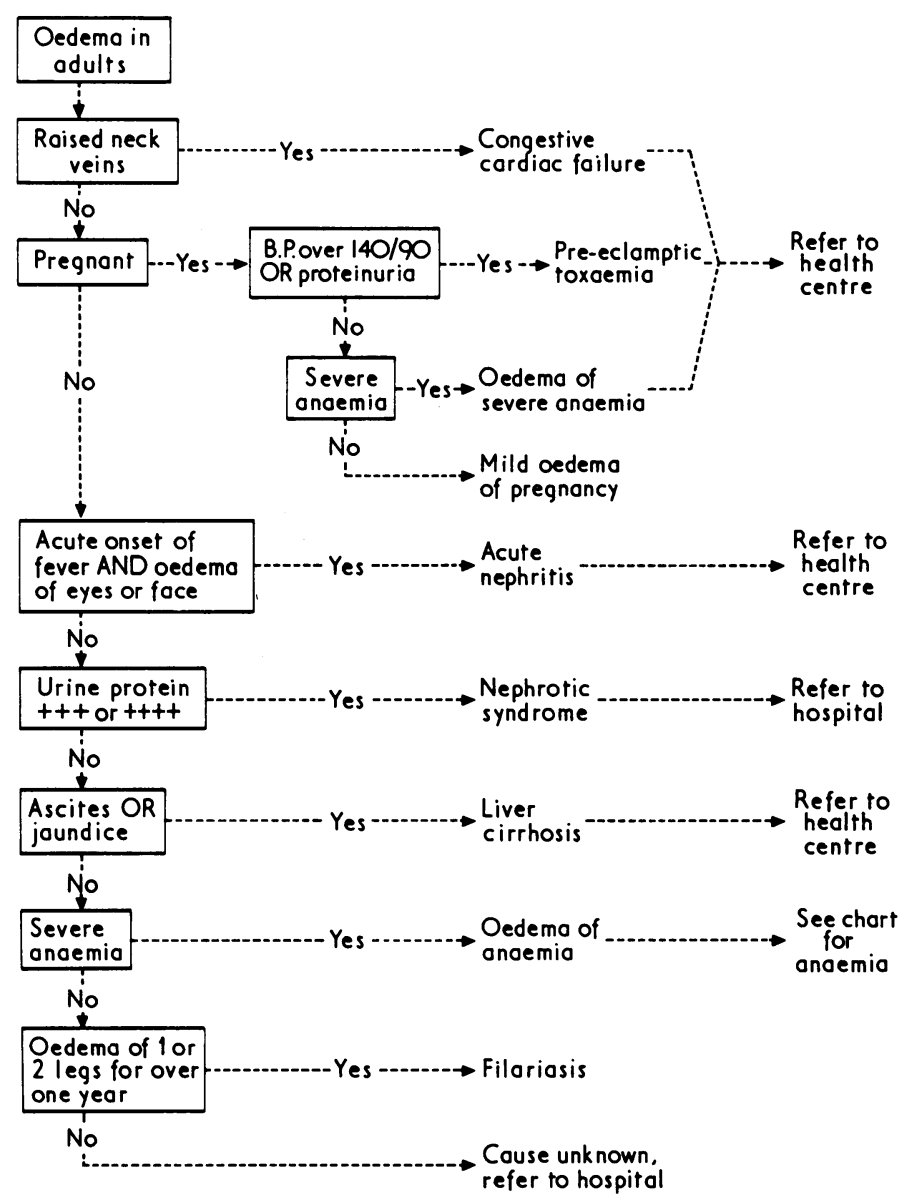

Flow chart for swelling of legs in adults.

\section{EVALUATION}

The flow charts were used by a third-year medical student who had done no practical clinical training. He used a chart for each symptom and recorded the diagnosis and time taken to use each chart. The student's diagnosis was then compared with that of an experienced doctor using conventional history taking and examination. The time taken by both methods was also compared.

\section{PATIENTS}

All patients admitted to the general medical wards of the Muhimbili National Teaching Hospital in Tanzania over a seven-week period were included in the study, as were patients admitted to the obstetric, paediatric, and gynaecology wards and those seen in the obstetric, gynaecology, and ophthalmic outpatient clinics. Altogether 1249 patients were seen and the charts were used on a total of 2030 occasions.

\section{Results}

\section{ACCURACY}

The closeness of agreement between the experienced doctors' diagnoses and those of the student using the flow charts is shown in table I. Some symptoms and signs are subdivided according to the age of the patient or the presence of an associated symptom, and for these more than one chart is used-for example, the four charts for severe abdominal pain relate to adults with fever, adults without fever, child with fever, and child without fever. Seven charts are excluded from table I because there were too few patients for proper evaluation.

On $1904(94 \%)$ of the 2030 occasions on which the charts were used the doctors agreed with the diagnosis. Of the 126 wrong diagnoses made with use of the charts 58 would have resulted in the patient being given the same treatment or being referred; 36 in the patient being given unnecessary treatment or being referred; and 32 in the patient having substantially different management, which represented $1.6 \%$ of all cases in the study.

Examination of the use of the charts for swelling of the legs in adults (table II) and vaginal bleeding (table III) showed agreement

TABle I-Percentage Agreement between Charts' and Doctors' Diagnoses (1249 Patients)

\% Agreement $\left\{\begin{array}{l}\text { Chart } \\ \text { Oomiting in adult } \\ \text { Body weakness } \\ \text { Weight loss in child } \\ \text { Joint pain in adult } \\ \text { Joint pain in child* } \\ \text { Dysphagia* } \\ \text { Incontinence* } \\ \text { Fits in adult* } \\ \text { Skin rash in child } \\ \text { Unconscious adult } \\ \text { Swelling of legs in child } \\ \text { Diarrhoea in child } \\ \text { Fever in adult } \\ \text { Fever in child } \\ \text { Headache } \\ \text { Swelling of legs in adult } \\ \text { Mild abdominal pain } \\ \text { Red eye } \\ \text { Dysmenorrhoea } \\ \text { Dyspnoea in adult } \\ \text { Dyspnoea in child } \\ \text { Cough in child } \\ \text { Anaemia in adult } \\ \text { Fits in child (2 charts) } \\ \text { Abdominal swelling (2 charts) } \\ \text { Mental confusion } \\ \text { Pruritus (2 charts) } \\ \text { Weight loss in adult } \\ \text { Severe abdominal pain (4 charts) } \\ \text { Chest pain } \\ \text { Haematuria* } \\ \text { Vaginal bleeding } \\ \text { Cough in adults } \\ \text { Anaemia in child } \\ \text { Jaundice in child (2 charts) } \\ \text { Backache (50\%)* } \\ \text { Vaginal discharge (75\%) }\end{array}\right.$

- Fewer than 15 cases.

TABLE II-Swelling of Legs in Adults

\begin{tabular}{|c|c|c|c|c|}
\hline \multirow{2}{*}{ Diseases } & & \multirow{2}{*}{$\begin{array}{l}\text { Cases Diagnosed } \\
\text { by Doctor }\end{array}$} & \multicolumn{2}{|c|}{ Chart Diagnosis } \\
\hline & & & Agree & Disagree \\
\hline 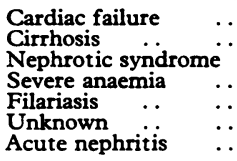 & $\begin{array}{l}\because \\
\because \\
\because \\
\because \\
\because\end{array}$ & $\begin{array}{r}45 \\
6 \\
5 \\
7 \\
6 \\
2 \\
1 \\
1\end{array}$ & $\begin{array}{r}45 \\
5 \\
5 \\
7 \\
6 \\
2 \\
1\end{array}$ & 1 \\
\hline
\end{tabular}

TABLE III-Vaginal Bleeding

\begin{tabular}{|c|c|c|c|}
\hline \multirow{2}{*}{ Diseases } & \multirow{2}{*}{$\begin{array}{l}\text { Cases Diagnosed } \\
\text { by Doctor }\end{array}$} & \multicolumn{2}{|c|}{ Chart Diagnosis } \\
\hline & & Agree & Disagree \\
\hline 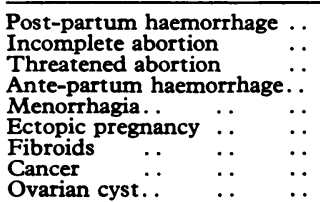 & $\begin{array}{r}4 \\
62 \\
31 \\
1 \\
10 \\
7 \\
17 \\
3 \\
1\end{array}$ & $\begin{array}{r}57 \\
17 \\
10 \\
7 \\
17 \\
3\end{array}$ & $\begin{array}{r}4 \\
5 \\
14 \\
1\end{array}$ \\
\hline
\end{tabular}


with the doctors' diagnoses in $99 \%$ ( 71 out of 72 cases) and $82 \%$ (111 out of 136 cases) of the cases, respectively, with the chart correctly diagnosing the most important causes of oedema (table II).

Out of the 136 occasions on which the chart for vaginal bleeding (table III) was used five cases of incomplete abortion were diagnosed as threatened abortion, and 13 cases of threatened abortion as incomplete abortion. Patients with an incomplete abortion who had little bleeding tended to be wrongly diagnosed as cases of threatened abortion. The doctor diagnosed an incomplete abortion on the basis of a vaginal examination, but the chart does not include this. Postpartum haemorrhage was not included on the original chart for vaginal bleeding, and four cases were wrongly diagnosed as incomplete abortions. The chart now includes this diagnosis. Ante-partum haemorrhage is on the charts for severe abdominal pain and the chart for shock but it was not on the early chart for vaginal bleeding, and one patient with this condition was diagnosed as a case of ectopic pregnancy. It is now included on the chart for vaginal bleeding. With use of the original chart for vaginal bleeding the wrong diagnosis would have resulted in the same management in five cases, unnecessary referral in 14 cases, and serious mismanagement in five cases. As a result of this evaluation the chart was redesigned to improve its diagnostic accuracy.

\section{TIME TAKEN TO REACH DIAGNOSIS}

The time taken by the student and doctors to diagnose 658 general medical cases is shown in table IV.

TABLE IV-Time Taken to Diagnose 658 General Medical Cases in Wards

\begin{tabular}{|c|c|c|c|}
\hline \multicolumn{2}{|c|}{ Chart Time } & \multicolumn{2}{|c|}{ Doctors' Time } \\
\hline Total & $\begin{array}{c}\text { Average } \\
\text { per Patient }\end{array}$ & Total & $\begin{array}{c}\text { Average } \\
\text { per Patient }\end{array}$ \\
\hline 23.1 Hours & 1.9 Minutes & 150 Hours & 13.7 Minutes \\
\hline
\end{tabular}

\section{REPEATABILITY OF CHARTS}

In a study to test the repeatability of the charts all the third-year rural medical-aid students in Kibaha Training School were divided at random into two groups, with 10 students in each group. The 10 students who came in the top half of the class in the examinations were equally distributed between the groups. Each day, one or two newly admitted patients who had not been seen by the students were selected for the study. On one day each student in group A diagnosed the patients by using the conventional method of history taking and examination, and students in group $B$ diagnosed the patients by using the charts. Next day group A used the charts and group B the conventional method. The diagnoses made by the students were compared with the diagnosis made by the medical officer in charge of the health centre. With the aid of the charts $98 \%$ of the diagnoses were made correctly, compared with only $70 \%$ of those made using the conventional method.

The charts were used a total of 193 times, and there was close agreement between all the students who used them. When a chart was used by different students for the same patient they made the correct diagnosis more often than the group without the charts. When the charts were used by the students who had made the wrong diagnosis using the conventional method all made the correct diagnosis.

\section{Conclusions}

This problem-orientated method of diagnosis has been shown to have acceptable levels of accuracy, repeatability, and rapidity. With practice, the student learns the pattern of sequences on the charts and soon develops confidence and skill in rapid problem solving without using them. Because of the high level of repeatability the method is of value in improving the performance of all students in a class.

For each diagnosis the charts indicate whether treatment can be given in a dispensary or at a health centre or hospital. This attempt to standardize referral patterns may lead to an improved quality of medical care. The charts are region-specific, and the epidemiological patterns of disease should be studied before they are used outside the African region. A complete account of this work is to be published as a book.

I wish to thank Professor W. Makene for his unceasing help and support, and also Dr. J. Everett, Dr. M. McCusker, and Professor Hamza for their advice. The design of the charts owes much to the valuable contributions from Dr. H. Gosling and Dr. A. Kapasi. I should also like to thank the following people who participated in the evaluation studies: Mr. Wella, Dr. Kiwia, Dr. Temba, Dr. Mgone, Dr. Malangalila, Dr. Rwamushaija, Mr. W. M. Mwenda, and all the students in the third-year class of Kibaha Training School in 1974. I acknowledge the co-operation of Dr. A. Ahmed, principal of Kibaha Training School. I am grateful to the African Medical Research Foundation for the financial support enabling this work to be reported.

Requests for reprints should be sent to me at: 21 St. Faith's Road, London SE21 8JD.

\section{Any Questions?}

\section{We publish below a selection of questions and answers of general interest}

\section{Huhner's Test}

\section{How effective is Huhner's test?}

This test is often known as the Sims-Huhner test, but is now best called the post-coital test. The vagina and cervix are tested within a few hours of intercourse to see if active spermatozoa can be found microscopically. The technique is described in most modern textbooks. It is simple and requires little equipment.

It is difficult to know what is meant by the test being effective. It tells whether intercourse is taking place properly, and whether the vaginal and cervical secretions are hostile to these particular spermatozoa. It is to be expected that vaginal secretions will kill off sperm after they have been in contact with the secretions for some time. The presence of motile sperm in the cervical mucus shows that they will probably reach the uterus. If no sperm are found after intercourse, then there may be technical errors in its performance, the man may be azoospermic, or there may be effluvium seminis in which the seminal fluid runs out of the vagina immediately after the sexual act. In performing the test the speculum may show a redundant fold of vagina below the cervix which may form a contraceptive barrier, rather like a Dutch cap, if penetration has not been deep enough. An alteration of coital technique may put this right, either with the woman superior or entry from behind. If there is cervical hostility there is probably a local antibody formation which kills off the spermatozoa. This might be overcome by abstention from intercourse for about six weeks or by the use of a condom for the same period, so preventing constant re-immunization by sperm coming into contact with the cervical epithelium. Like all other tests it may be said to be effective when taken in conjunction with all the other evidence obtained in infertility investigations. It is evidence which should be to hand in all infertility investigations. 